\title{
PARCELAMENTO DA ADUBAÇÃO E DA FERTIRRIGAÇÃO NA PRODUÇÃO DE PALMITO PUPUNHA NO NOROESTE PAULISTA ${ }^{1}$
}

\author{
JOSÉ ALVES JÚNIOR ${ }^{2}$, FERNANDO B. T. HERNANDEZ ${ }^{3}$, RONALDO A. SANTOS ${ }^{4}$, \\ ADRIANO S. LOPES
}

\begin{abstract}
RESUMO: O palmito é um alimento muito apreciado na culinária brasileira e mundial, e entre as várias espécies de palmeira produtora, a pupunha se destaca por apresentar precocidade de produção, perfilhamento, rusticidade e boas características de processamento. Introduzida no Noroeste Paulista em 1994, a cultura da pupunha é vista por técnicos e produtores como bastante promissora na região, porém carente de informações técnicas, entre as quais a maneira e a época de aplicação de fertilizantes. Face a isso, foi instalado um experimento na UNESP, Câmpus de Ilha Solteira - SP, em área irrigada por microaspersão, com pupunheiras espaçadas de $2 \times 1 \mathrm{~m}$ entre linhas e entre plantas, respectivamente. Os tratamentos foram assim constituídos: adubação manual na linha de plantio a cada três meses, fertirrigação mensal, fertirrigação bimestral e fertirrigação trimestral. Aos 22 meses do plantio (2-3-2000), realizou-se a primeira colheita e, a partir dessa, foram realizadas colheitas bimestrais. Considerando as onze colheitas, a fertirrigação bimestral e trimestral apresentaram produção de 2,60 e 1,84 $\mathrm{t} \mathrm{ha}^{-1}$ de palmito, respectivamente, enquanto a adubação manual e a fertirrigação mensal apresentaram produtividades de 3,2 e $2,69 \mathrm{t} \mathrm{ha}^{-1}$, respectivamente, mostrando que a adubação manual e a fertirrigação mensal e bimestral são as melhores práticas para lavouras em estágios iniciais de produção.
\end{abstract}

PALAVRAS-CHAVE: Bactris gasipaes, microaspersão, fertirrigação.

\section{FRACTIONING FERTILIZATION AND FERTIGATION IN PEACH PALM AND PALM HEART PRODUCTION IN THE NORTHWESTERN REGION OF SÃO PAULO STATE, BRAZIL}

SUMMARY: Palm heart is a very appreciated meal in the Brazilian and world cuisine. Among several edible palm tree species, pejibaye excels due to early yield, tillering, rusticity and ideal processing traits. It was introduced in the northwestern region of São Paulo in 1994, and it is considered by extensionists and growers as a promising crop for the region, despite the lack in technical information, among them the method and time of fertilizer application. Those factors leaded us to develop experiment in a stand irrigated by microsprinklers, in which pejibaye plant spacing was of $2 \times 1 \mathrm{~m}$ (among rows $\mathrm{x}$ between plants). There were four treatments: manual fertilization in the rows every three months; monthly fertigation, bimontly fertigation and fertigation every three months. Twentytwo days after planting (March 2, 2000) the first harvest was done and thereafter at every two months. Considering the eleven yields, fertigation every three months and bimonthly fertigation yielded 2.60 and $1.84 \mathrm{t} \mathrm{ha}^{-1}$ of palm heart, respectively, while for manual and monthly fertigation yield was of 3.23 and $2.69 \mathrm{tha}^{-1}$, respectively. These results suggest that manual fertilization in the rows every three months, monthly and bimontly fertigation are the best practices for crops in early stages of production.

KEYWORDS: Bactris gasipaes, microsprinkler, fertigation.

\footnotetext{
${ }^{1}$ Trabalho realizado com apoio financeiro da Fundação de Amparo à Pesquisa do Estado de São Paulo - FAPESP. Processo 99/02937-0

${ }^{2}$ Eng ${ }^{0}$ Agrônomo, Mestrando em Irrigação e Drenagem na Escola Superior de Agricultura "Luiz de Queiroz" - ESALQ/USP, Departamento de Engenharia Rural, Fone: (0XX19) 429.4100, Piracicaba - SP, e-mail: jalves@esalq.usp.br

${ }^{3}$ Prof. Dr., Pesquisador da FEIS/UNESP, Departamento de Fitossanidade, Engenharia Rural e Solos, e-mail: fbthtang@agr.feis.unesp.br

${ }^{4}$ Eng ${ }^{0}$ Agrônomo pela FEIS/UNESP e Mestrando em Irrigação e Drenagem - ESALQ/USP, email: santosra@esalq.usp.br

${ }^{5}$ Eng ${ }^{\text {o }}$ Agrônomo, Prof. Dr., Universidade Estadual do Mato Grosso do Sul, UEMS, Aquidauana - MS, e-mail: lopes@ uems.br

Recebido pelo Conselho Editorial em: 10-9-2002

Aprovado pelo Conselho Editorial em: 20-7-2004
} 


\section{INTRODUÇÃO}

Antes da década de 1960, o Estado de São Paulo era o principal produtor brasileiro de palmito, sendo extraído da palmeira juçara (Euterpe edulis Mart.). Por volta de 1980, ocorreu a primeira crise na exploração extrativista do palmito. Rapidamente, as principais empresas processadoras de palmito se mudaram para o Estado do Pará, então com extensas reservas de açaizeiros (Euterpe oleracea Mart.). Atualmente, esse Estado é o primeiro produtor, com cerca de $92 \%$ da produção brasileira de palmito, seguido por São Paulo, com apenas 4\% (BOVI, 1997).

De acordo com FLORI e D'OLIVEIRA (1995), a pupunha (Bactris gasipaes H.B.K.) se apresenta hoje como a melhor alternativa de cultivo para a produção racional de palmito, tendo em vista as suas qualidades agronômicas, industriais e comerciais. Essa palmeira apresenta bom perfilhamento, precocidade de colheita, boa produtividade e rusticidade. Nos últimos anos, com a seleção e produção de plantas sem espinhos, consolidou-se mais uma vantagem dessa espécie. $\mathrm{O}$ palmito obtido da pupunha apresenta a característica de não sofrer escurecimento após o descascamento, que é comum tanto no palmito açaí, como no juçara.

A cultura da pupunha foi introduzida no Noroeste Paulista pela Área de Hidráulica e Irrigação da Faculdade de Engenharia de Ilha Solteira - UNESP, em 1994. A resposta agronômica da cultura frente à irrigação, adubação e número de perfilhos tem sido avaliada desde então, com resultados que deixam claro a aptidão da cultura nas condições edafoclimáticas da região. É considerada uma cultura que se adapta muito bem às condições de alta temperatura, alta pluviosidade e, também, a solos arenosos. O Noroeste Paulista atende bem a essas exigências, à exceção do regime hídrico, que, apesar de apresentar um histórico de precipitação de $1.232 \mathrm{~mm}$ anuais, tem má distribuição, concentrando-se entre outubro e março, e apresentando um déficit hídrico entre abril e dezembro (HERNANDEZ et al., 1995).

Vários são os produtores que estão introduzindo em suas terras a cultura da pupunha e os municípios de Ilha Solteira, Santa Mercedes e Santa Fé do Sul já possuem uma área expressiva de plantio, inclusive em fase de produção. No entanto, é consenso entre os produtores que a irrigação é uma prática obrigatória para o sucesso do empreendimento, tendo inclusive lavouras irrigadas que apresentaram início de produção aos 17 meses, devendo-se isso, provavelmente, ao fornecimento regular de água e nutrientes.

A obrigatoriedade da irrigação é consenso entre os produtores, porém o mesmo não ocorre em relação ao uso da fertirrigação, ficando o consenso apenas para os técnicos que trabalham na área de irrigação. Também, as recomendações hoje vigentes para a adubação (BOVI \& CANTARELLA, 1996) não fazem a diferenciação entre o fornecimento de adubos sólidos aplicados na superfície do solo e o uso da fertirrigação.

Dessa maneira, este trabalho teve o objetivo de identificar a melhor época e forma de aplicação dos nutrientes, manual (sólido) ou via fertirrigação e o seu efeito sobre as características produtivas da cultura.

\section{MATERIAL E MÉTODOS}

A instalação do experimento foi feita na Área Experimental de Agricultura Irrigada da Fazenda de Ensino e Pesquisa - Pomar da Faculdade de Engenharia de Ilha Solteira - UNESP, com coordenadas geográficas $20^{\circ} 25^{\prime} 23^{\prime \prime}$ de latitude sul e $51^{\circ} 21^{\prime} 13^{\prime \prime}$ de longitude oeste, e altitude média de $335 \mathrm{~m}$. Segundo a classificação de Köeppen, a região possui um clima do tipo Aw, definido como tropical úmido, com estação chuvosa no verão e seca no inverno, apresentando temperatura média anual de $24,5^{\circ} \mathrm{C}$, precipitação média anual de $1.232 \mathrm{~mm}$ e umidade relativa média anual de $64,8 \%$ (HERNANDEZ et al., 1995). 
De acordo com o IPT (1981) citado por CARVALHO \& MELLO (1989), o solo da área foi classificado como Podzólico Vermelho-Escuro, eutrófico, textura arenosa. O experimento foi instalado em abril de 1998, com o plantio das mudas no espaçamento de 2 x $1 \mathrm{~m}$ (entre linhas e entre plantas, respectivamente). Foram aplicados por cova $10 \mathrm{~g}$ de cloreto de potássio e $110 \mathrm{~g}$ de superfosfato simples (em pó). Dois meses após o plantio, foi feita adubação em cobertura com $10 \mathrm{~g}$ de uréia por planta. Essa adubação foi realizada manualmente, pois se fosse feita via irrigação, a eficiência do fertilizante seria muito baixa, devido à pequena profundidade das raízes na ocasião. Dessa maneira, e seguindo a recomendação de BOVI \& CANTARELLA (1996), a adubação foi iniciada aos seis meses após o plantio.

$\mathrm{Na}$ Tabela 1, apresenta-se o resultado da análise química do solo antes do plantio das mudas no campo.

TABELA 1 - Análise química do solo na instalação do experimento.

\begin{tabular}{cccccccccc}
\hline $\begin{array}{c}\mathrm{P} \\
\mathrm{mg} \mathrm{dm}^{-3}\end{array}$ & $\begin{array}{c}\mathrm{M} . \mathrm{O} . \\
\mathrm{g} \mathrm{dm}^{-3}\end{array}$ & $\mathrm{pH}$ & $\mathrm{K}$ & $\mathrm{Ca}$ & $\mathrm{Mg}$ & $\begin{array}{c}\mathrm{H}+\mathrm{Al} \\
\mathrm{mmol}_{\mathrm{c}} \mathrm{dm}^{-3}\end{array}$ & $\mathrm{~S}$ & $\mathrm{CTC}$ & $\begin{array}{c}\mathrm{V} \\
\%\end{array}$ \\
\hline 20 & 17 & 5,0 & 2,5 & 20 & 4 & 20 & 27 & 47 & 57 \\
\hline
\end{tabular}

O sistema de irrigação utilizado foi de microaspersão, com um microaspersor para cada oito plantas. O microaspersor utilizado foi o modelo Carborundum MS-III, cuja vazão em teste de campo foi de $101,8 \mathrm{~L} \mathrm{~h}^{-1}$, operando à pressão de serviço de $203,3 \mathrm{kPa}$. O cabeçal de controle foi composto por dois filtros de areia, um filtro de disco de 120 mesh e um injetor tipo venturi para aplicação de fertilizantes, sendo o sistema operado automaticamente. Apenas as retrolavagens foram feitas manualmente.

A irrigação foi feita diariamente, e os tratamentos instalados receberam a mesma dotação de água, sendo o tempo de irrigação dependente das condições climáticas locais e calculado segundo a eq.(1) (VERMEIREN \& JOBLING, 1997):

$$
\mathrm{TI}=\frac{\mathrm{E} \text { e ECA Kr}}{\mathrm{q} n \text { ef }} \mathrm{K}
$$

em que,

TI - tempo de irrigação por planta, horas;

$\mathrm{E}$ - espaçamento entre linhas, $\mathrm{m}$;

e - espaçamento entre plantas, $\mathrm{m}$;

ECA - evaporação do tanque Classe A, mm;

$\mathrm{K}_{\mathrm{r}}$ - coeficiente de cobertura do solo;

$\mathrm{q}$ - vazão do emissor, $\mathrm{L} \mathrm{h}^{-1}$;

n - número de emissores por planta;

$\mathrm{K}$ - fator de consumo $=\mathrm{Kp} \mathrm{Kc}, \mathrm{e}$

ef - eficiência.

Inicialmente, utilizou-se $\mathrm{Kr}$ de 0,3 e, a partir dos quatro meses após o plantio (agosto de 1998), passou-se a utilizar o valor de 0,6, pois as plantas ainda se encontravam na fase jovem. Aos 21 meses após o plantio (janeiro de 2000), esse fator passou a ser 0,9 (LOPES et al., 2000).

$\mathrm{O}$ fator $\mathrm{K}$ foi determinado experimentalmente em Ilha Solteira e, até o primeiro ano de produção, 0,75 foi o fator que melhor resultado apresentou, correspondendo a um $\mathrm{Kc}=1,0$; a partir do segundo ano de produção, o fator que melhor resultado apresentou foi 1,0; correspondendo a um $\mathrm{Kc}=1,33$ (LOPES et al., 2000), sendo esses utilizados neste experimento. 
O experimento foi composto de quatro tratamentos e quatro repetições, sendo o delineamento experimental inteiramente casualizado. Cada parcela foi constituída por 12 plantas, totalizando 48 plantas por tratamento. A bordadura foi formada por duas plantas localizadas nas extremidades de cada linha de plantio, assim como a primeira e última linha de cada tratamento.

É importante informar que, devido à desuniformidade genética das plantas, foi exigido grande número de plantas por repetição (12 plantas), que possibilitaram, portanto, a obtenção de informações mais precisas sobre o comportamento da cultura mesmo necessitando de grande área para a experimentação. Para BOVI (1983), citado por BARBOSA (1993), todas as populações de pupunheiras perfilham, embora ocorra uma variabilidade muito grande entre plantas, existindo plantas que perfilham logo após seis meses de plantio definitivo no campo e outras somente após o corte da planta-mãe. Sabe-se que, estatisticamente, é necessário um número mínimo de graus de liberdade para validar um trabalho científico. Porém, devido a essa variabilidade, adotaram-se apenas quatro tratamentos e quatro repetições por acreditar que, se considerada cada planta uma repetição, teria um alto coeficiente de variação.

Foram utilizados a uréia e o sulfato de amônio como fontes de nitrogênio, superfosfato triplo e o superfosfato simples como fonte de fósforo e o cloreto de potássio como fonte de potássio para o parcelamento das adubações de cobertura no seguinte modo: tratamento 1 - adubação de nitrogênio, fósforo e potássio $(\mathrm{N}, \mathrm{P}, \mathrm{K})$ em cobertura via solo, quatro vezes ao ano; tratamento 2 - adubação ( $\mathrm{N}$ e K) em cobertura via fertirrigação, 12 vezes ao ano, e aplicação manual de fósforo, quatro vezes ao ano; tratamento 3 - adubação ( $\mathrm{N}$ e K) em cobertura via fertirrigação, seis vezes ao ano, e aplicação manual de fósforo, quatro vezes ao ano, e tratamento 4 - adubação ( $\mathrm{N}$ e K) em cobertura via fertirrigação e aplicação manual de fósforo, quatro vezes ao ano.

No tratamento 1, todos os adubos foram aplicados manualmente em faixas, em ambos os lados, distantes de 0,30 a $0,50 \mathrm{~m}$ do tronco.

As doses de fertilizantes aplicadas totalizaram anualmente 230 e $300 \mathrm{~kg}$ de N, 30 e $50 \mathrm{~kg}$ de $\mathrm{P}_{2} \mathrm{O}_{5}$ e 100 e $140 \mathrm{~kg}$ de $\mathrm{K}_{2} 0$ por hectare, no primeiro e segundo anos de produção, respectivamente.

A plantas foram conduzidas com livre perfilhamento sem desbaste de perfilhos.

As colheitas foram realizadas a cada dois meses, sendo a primeira realizada aos 22 meses e a última aos 42 meses do plantio, totalizando cinco colheitas no primeiro ano (2000) e seis colheitas no segundo ano de produção (2001). O ponto de corte adotado como padrão foi o perímetro de $0,3 \mathrm{~m}$ a $0,5 \mathrm{~m}$ do solo ou $1,8 \mathrm{~m}$ de altura do nível do solo até a folha mais nova desdobrada.

O palmito produzido foi classificado em primeira, segunda e terceira, sendo os dois primeiros cortados com $9 \mathrm{~cm}$ de comprimento e diferenciados somente em função da resistência ao corte (o de segunda é ligeiramente mais fibroso que o de primeira). Já o de terceira é a base do palmito que é processado em pequenos pedaços.

\section{RESULTADOS E DISCUSSÃO}

Os resultados obtidos no final do estudo mostraram que não houve diferenças significativas entre os tratamentos 1; 2 e 3 (adubação manual, fertirrigação mensal e bimestral, respectivamente) sendo o tratamento 4 (fertirrigação trimestral) o que apresentou menor produção, tornando-o diferente dos tratamentos 1 e 2, a 5\% de probabilidade (Tabela 2).

A produção de palmito por estipe não diferiu estatisticamente entre os tratamentos a $5 \%$ de significância, como pode ser observado na Tabela 3. Isso mostra que os tratamentos diferiram, entre si, em função do número de estipes colhidas, como pode ser observado na Tabela 4. 
TABELA 2. Valores médios da produção (t/ha) de palmito de pupunha referente às onze primeiras colheitas realizadas dos 22 até os 42 meses de idade (dois primeiros anos de produção, 2000 e 2001).

\begin{tabular}{lc}
\hline Tratamento & Produção $\left(\mathrm{t} \mathrm{ha}^{-1}\right)$ \\
\hline Adubação manual trimestral & $3,234 \mathrm{~A}$ \\
Fertirrigação mensal & $2,698 \mathrm{~A}$ \\
Fertirrigação bimestral & $2,604 \mathrm{AB}$ \\
Fertirrigação trimestral & $1,847 \mathrm{~B}$ \\
\hline
\end{tabular}

Coeficiente de variação $=15,01 \%$; DMS $(5 \%)=0,8185$; Médias seguidas de mesma letra não diferem estatisticamente entre si, pelo teste de Tukey, a 5\% de probabilidade.

TABELA 3. Produção média de palmito (gramas) por estipe nos dois primeiros anos de produção (2000 e 2001).

\begin{tabular}{lcccc}
\hline \multicolumn{1}{c}{ Tratamento } & Palmito (primeira) & Palmito (segunda) & Palmito (terceira) & Total \\
\hline Adubação manual trimestral & 132,28 & 29,36 & 79,11 & $240,75 \mathrm{~A}$ \\
Fertirrigação mensal & 140,55 & 40,41 & 88,67 & $269,63 \mathrm{~A}$ \\
Fertirrigação bimestral & 110,52 & 24,98 & 77,51 & $188,96 \mathrm{~A}$ \\
Fertirrigação trimestral & 106,88 & 25,03 & 79,31 & $235,28 \mathrm{~A}$ \\
\hline
\end{tabular}

Coeficiente de variação = 18,83\%; DMS $(5 \%)=84,60$; Médias seguidas de mesma letra, na mesma coluna, não diferem estatisticamente entre si, pelo teste de Tukey, a $5 \%$ de probabilidade.

As colheitas bimestrais das plantas em condições de processamento permitiram a elaboração da Tabela 4, com as porcentagens de plantas colhidas no final de cada ano de produção, sendo cinco e seis colheitas realizadas no primeiro e segundo anos de produção, respectivamente.

A porcentagem de plantas colhidas é a relação entre a quantidade de estipes colhidos no período em função do número de plantas na área (5.000 plantas por hectare).

TABELA 4. Porcentagem acumulada de plantas colhidas no final da quinta colheita (final do primeiro ano de produção, 2001) e da décima primeira colheita (final do segundo ano de produção, 2002).

\begin{tabular}{lcc}
\hline \multirow{2}{*}{ Tratamento } & Primeiro Ano de Produção & Segundo Ano de Produção \\
\cline { 2 - 4 } & \multicolumn{3}{c}{} \\
\hline Adubação manual trimestral & 93,7 & 241,7 \\
Fertirrigação mensal & 85,4 & 195,8 \\
Fertirrigação bimestral & 91,7 & 179,2 \\
Fertirrigação trimestral & 79,2 & 162,5 \\
\hline
\end{tabular}

* O valor de 100\% significa que se realizou o corte de pelo menos uma estipe por touceira por ano (5.000 estipes).

Em 2002, após 11 colheitas, foi possível obter uma porcentagem acumulada de plantas cortadas superior a $200 \%$. Nota-se que, por exemplo, o tratamento com adubação manual trimestral foi de $241,7 \%$ de plantas colhidas, sendo $93,7 \%$ de plantas colhidas no primeiro ano e 148,0\% no segundo ano de produção. Isso significa que o estipe principal de quase todas as touceiras foi colhido no primeiro ano de produção, e quase um estipe e meio de perfilhos colhido por touceira no segundo ano de produção, ou seja, em uma população de 5.000 plantas por hectare, foram colhidos 4.685 e 7.400 estipes no primeiro e segundo anos de produção, respectivamente.

Dentre os parâmetros utilizados para determinar as plantas a serem colhidas, todos os estipes principais foram colhidos em função do perímetro. Para o segundo ano de produção, o parâmetro que 
predominou foi a altura de plantas devido ao estiolamento dos perfilhos. Em média o perímetro e a altura dos estipes colhidos foram $0,32 \mathrm{~m}$ e $1,71 \mathrm{~m} ; 0,27 \mathrm{~m}$ e $1,86 \mathrm{~m}$ para o primeiro e segundo anos de produção, respectivamente, o que evidencia o estiolamento e coloca em questionamento $o$ espaçamento empregado.

Em relação à produção total de palmito obtida nos melhores tratamentos $\left(1,5 \mathrm{t} \mathrm{ha}^{-1}\right.$ por ano em média), em geral, pode ser considerada baixa. HERNADEZ et al. (2001) apresentaram dados médios dos quatro primeiros anos de produção de palmito pupunha em Ilha Solteira -SP, que foi de 2,4 e $3,1 \mathrm{t} \mathrm{ha}^{-1}$ por ano em áreas fertirrigadas mensalmente e irrigadas com $75 \%$ da evaporação do tanque Classe A (ECA) e $100 \%$ da ECA, respectivamente

Diante da recomendação atual de cultivo (HERNANDEZ et al., 2001) em que o uso da irrigação é uma prática indispensável para o cultivo da pupunha na região, os dados deste estudo, em geral, mostraram que a adubação manual (tradicional) pode ser substituída pela fertirrigação mensal ou bimestral, sem causar perda significativa de produtividade, pois os resultados não diferiram quando se realizou a adubação da cultura de forma manual (quatro vezes ao ano) e a fertirrigação parcelada mensal e bimestralmente. Já a produção do tratamento 4 (fertirrigação quatro vezes ao ano) foi menor, inviabilizando a fertirrigação trimestralmente.

Entretanto, a produção, entre os tratamentos estudados, mostra que a adubação manual apresentou uma produtividade de $0,5 \mathrm{tha}^{-1}$ a mais em relação às produções de outros tratamentos estatisticamente iguais. Dessa forma, parece indispensável relacionar os resultados deste estudo com o custo de produção, antes de optar pelo uso da fertirrigação.

\section{CONCLUSÕES}

A adubação na cultura da pupunha é uma prática que pode ser realizada com aplicação dos fertilizantes via solo ou via fertirrigação. A adubação via solo, a cada três meses manualmente, pode ser substituída pela fertirrigação desde que seja parcelada mensalmente ou bimestralmente.

\section{AGRADECIMENTOS}

À Fundação de Amparo a Pesquisa do Estado de São Paulo - FAPESP, pelo apoio financeiro, e à equipe da Área de Hidráulica e Irrigação - DEFERS da UNESP - Câmpus de Ilha Solteira - SP, pela colaboração na realização deste trabalho.

\section{REFERÊNCIAS}

BARBOSA, A.M.M. Pupunha (Bactris gasipaes). In: ENCONTRO SOBRE PRODUÇÃO DE PALMITO,1., 1993, Piracicaba. Anais... Piracicaba: Centro Acadêmico "Luiz de Queiroz", 1993. p.8-11.

BOVI, M.L.A. Palmito pupunha: informações básicas para o cultivo. Campinas: IAC, 1997. 11 p.

BOVI, M.L.A.; CANTARELLA, H. Pupunha para extração de palmito. In: RAIJ. B.V.; SILVA, N.M.; BATAGLIA, O.C.; QUAGGIO, J.A.; HIROCE, R.; CANTARELA, H.; BELINAZZI JÚNIOR, R.; DECHEN, A.R.; TRANI, P.E. (Ed.). Recomendações de adubação e calagem para o Estado de São Paulo. 2.ed. Campinas: IAC, 1996. p.240-2. (Boletim Técnico, 100).

CARVALHO, M.P.; MELLO, L.M.M. Classificação da capacidade de uso da terra do antigo pomar da Fazenda de Ensino e Pesquisa da Faculdade de Engenharia de Ilha Solteira - FEIS/UNESP. Ilha Solteira: UNESP/FEIS, 1989. 46 p.

FLORI, J.E., D'OLIVEIRA, L.O.B. O cultivo da pupunha sob irrigação no semi-árido do Nordeste brasileiro. Petrolina: EMBRAPA/CPTSA, 1995. 3 p. (Comunicado Técnico, 62). 
HERNANDEZ, F.B.T.; LEMOS FILHO, M.A.F.; BUZETTI, S. Software HIDRISA e o balanço hídrico de Ilha Solteira. Ilha Solteira: UNESP/FEIS/Área de Hidráulica e Irrigação, 1995. 45 p. (Série irrigação, 1).

HERNANDEZ, F.B.T.; ALVES JÚNIOR, J.; LOPES, A.S. Irrigação na cultura da pupunha. In: CURSO SOBRE CULTIVO PROCESSAMENTO E COMERCIALIZAÇÃO DE PALMITO PUPUNHA, 1., 2001, Londrina: IAPAR, 2001. p.107-26 (Circular Técnica, 11)

LOPES, A S.; HERNANDEZ, F.B.T.; ALVES JÚNIOR, J.; VALÉRIO FILHO, W.V. Manejo da irrigação na Cultura da Pupunha no Noroeste Paulista. In: CONGRESSO BRASILEIRO DE ENGENHARIA AGRÍCOLA, 29., 2000, Fortaleza. Anais... Fortaleza: Sociedade Brasileira de Engenharia Agrícola, 2000. 1 CD ROM.

VERMEIREN, G.A.; JOBLING, G.A. Irrigação localizada. Traduçãode GHEYI, H.R.;

DAMASCENO, F.A.V.; SILVA JÚNIOR, L.G.A.; MEDEIROS, J.F. Campina Grande: UFPB, 1997. 184 p. (Estudos FAO: Irrigação e Drenagem, 36). 